\title{
HABILIDOSAS E BONITAS: AS CONSIDERAÇÕES DE DUAS ATLETAS DE FUTEBOL SOBRE A FORMAÇÃO DE SUAS IDENTIDADES
}

\author{
SKILFUL AND BEAUTIFUL: TWO FEMALE FOOTBALL PLAYERS' \\ CONSIDERATIONS ABOUT THE CONSTRUCTION OF THEIR IDENTITIES
}

\section{HÁBILES Y HERMOSAS: CONSIDERACIONES DE DOS ATLETAS DE FÚTBOL ACERCA DE LA FORMACIÓN DE SUS IDENTIDADES}

\author{
Maria Thereza Oliveira Souza*, André Mendes Capraro*, \\ Marcelo Moraes e Silva*
}

\begin{abstract}
Palavras chave:
Futebol.

Atletas.

Identidade de

gênero.

Mulheres.

Resumo: Entendendo o futebol como um fenômeno que não apenas reproduz distinções de gênero, mas que também as cria e reforça, o objetivo deste trabalho foi identificar como se posicionam atletas de futebol feminino com longa vivência na modalidade $e$ que então, em alguns aspectos, desrespeitaram normas de gênero. A metodologia da História Oral foi utilizada para elaboração e análise de entrevistas realizadas com duas ex-atletas da seleção brasileira. Foram percebidas em suas reminiscências marcas de pressões exercidas para uma adequação aos padrões de gênero. Além disso, no intuito de consolidar suas identidades, elas disseram que sabem da existência e reincidência de casos de preconceito contra mulheres atletas de futebol, mas se disseram imunes pelo fato de terem características femininas bem marcadas. Por fim, foi notável que ao mesmo tempo em que se sentem prejudicadas por algumas pressões exercidas, de certa forma, elas agem na consolidação dos padrões.
\end{abstract}

Keywords:

Soccer.

Athletes.

Gender Identity.

Women.

Palabras clave:

Fútbol.

Atletas.

Identidad de género.

Mujeres.

Abstract: Understanding football as a phenomenon that not only reproduces gender distinctions but also creates and reinforces them, this study identifies stances taken by experienced female football players who disregarded gender norms in some ways. Oral History methodology was used to prepare and analyze interviews with two former members of the Brazilian national team. Their reminiscences showed marks of pressure to adapt to gender patterns. Moreover, in order to consolidate their identities, they said they know recurrent cases of bias against women who play football but considered themselves immune to them because they have well-marked female characteristics. Finally, while they feel hurt by some pressures, they somehow act to consolidate the standards.

Resumen: Entendiendo el fútbol como un fenómeno que no solo reproduce distinciones de género, sino que también las crea y refuerza, el objetivo de este trabajo ha sido identificar la postura que adoptan atletas de fútbol femenino con gran experiencia en esta modalidad y que, de alguna manera, han incumplido normas de género. La Historia Oral fue utilizada para la elaboración y el análisis de entrevistas realizadas con dos exatletas de la selección brasileña. Fueron percibidas en sus memorias marcas de presiones ejercidas para una adecuación a los estándares de género. Además, buscando consolidar sus identidades, dijeron que saben de la existencia y recurrencia de casos de prejuicio contra mujeres atletas de fútbol, pero afirmaron que son inmunes debido a que tienen características femeninas muy marcadas. Por último, destaca que pese a que se sienten perjudicadas por algunas presiones, en cierto modo ellas mismas actúan en la consolidación de esos estándares.
*Universidade Federal do Paraná. Curitiba, PR, Brasil. E-mail: mariathereza_souza93@yahoo. com.br;

andrecapraro@onda.com.br; moraes_marc@yahoo.com.br

Recebido em: 18-05-2016 Aprovado em: 25-05-2017

(c) (i) () Licence 


\section{INTRODUÇÃOO}

Como mostram Moraes e Silva e Fontoura (2011), utilizando como parâmetro a Revista Brasileira de Educação Física, desde a década de 1940 os corpos femininos são orientados e controlados por discursos. Discursos que no período analisado eram pautados pelo saber médico e caracterizados por objetivos higienistas/eugenistas que visavam tornar as mulheres saudáveis e aptas a uma boa maternidade para gerar descendentes fortes. Nesse mesmo momento, elas iniciavam, conforme apontam os autores, uma ruptura com a exclusividade dos papéis privados que lhes eram atribuídos - como a realização de tarefas de organização e limpeza doméstica ou companhia e assistência ao marido, filhos e irmãos -, ao passo que o desenvolvimento de atividades industriais e comerciais crescia em ritmo acelerado e assim requisitava sua presença. Dessa forma, elas, discretamente, passaram também a figurar em práticas esportivas.

Apesar disso, os citados discursos, oriundos principalmente de médicos, aparentavam temer que essas mulheres perdessem suas características "naturais" ao praticar esportes e, portanto, indicavam cuidados e estabeleciam normas para que essa prática se mantivesse dentro dos limites sociais e também do adequado ponto de não prejudicar sua principal função - a maternidade. Esses aspectos foram trabalhados por Silvana Goellner em sua pesquisa sobre os discursos presentes na Revista Educação Physica:

Para o corpo da mulher proliferam técnicas e estratégias de autoconhecimento e autocontrole que consistem não na restrição a sua movimentação mas, exatamente, no seu contrário: através do movimento e pelo movimento são estabelecidas formas sutis de aplicar um rígido controle sobre si mesma (GOELLNER, 1999, p. 165).

Foi nesse sentido que as práticas incentivadas e ditas normais ao estilo feminino de ser eram, principalmente, a ginástica, a dança e a natação, modalidades que não requisitavam 0 emprego de demasiada virilidade e, assim, eram capazes de manter a graciosidade e beleza dos corpos e comportamentos das mulheres (GOELLNER, 1999).

Tais discursos eram tão aceitos que, sob a orientação de um documento elaborado pelo General Newton Cavalcanti em 1941 e aprovado pelo Conselho Nacional de Desportos (CND) em 1965, foi estabelecido que as mulheres fossem proibidas de praticar esportes como futebol, rúgbi, lutas e halterofilismo (GOELLNER, 2005b). O documento só foi revogado em 1979, mas as tentativas de normatizações continuaram em voga de forma menos oficial, já que as atletas ainda se viam pressionadas a se manter dentro dos limites estabelecidos socialmente para as mulheres.

No caso específico do futebol feminino, Salvini e Marchi Jr. (2013) mostram que a tradicional revista esportiva Placar, então na década de 1980, além de trazer constantes informações sobre a equipe Esporte Clube Radar, usualmente publicava reportagens sobre aspectos físicos e estéticos de atletas, inclusive veiculando fotos de jogadoras apenas de calcinha e a camisa de seus clubes para "promover" o esporte. Também era comum nas páginas de tal revista a repercussão de jogos de atrizes da emissora Rede Globo, nos quais a primazia técnica era o que menos importava. Assim, evidenciava-se que, apesar de "[...] 0 avanço das mulheres no mundo dos esportes [ser] um fenômeno amplamente reconhecido hoje em dia" (ADELMAN, 2006, p. 14), a repercussão do futebol feminino, muitas vezes, se deu de 
maneira a tratar as atletas como belas e frágeis (MARTINS; MORAES, 2007). Características estas constituintes das normatizações relacionadas ao sexo feminino. Normatizações que foram denominadas de gênero - conceito que a pesquisadora estadunidense Joan Scott define como: "[...] um elemento constitutivo de relações sociais baseadas nas diferenças percebidas entre os sexos" e como "[...] uma forma primária de dar significado às relações de poder" (SCOTT, 1995, p. 86) $)^{1}$. Na maioria das vezes, essas normatizações são baseadas no:

[...] argumento de que homens e mulheres são biologicamente distintos e que a relação entre ambos decorre dessa distinção, que é complementar e na qual cada um deve desempenhar um papel determinado secularmente, acaba por ter o caráter de argumento final, irrecorrível. Seja no âmbito do senso comum, seja revestida por uma linguagem 'científica', a distinção biológica, ou melhor, a distinção sexual, serve para compreender - e justificar - a desigualdade social (LOURO, 1997, p. 20-21).

Além disso, o esporte, como defende Silvana Goellner(2005a), produz essas desigualdades e diferenciações de gênero e não apenas reproduz aquilo que está posto na sociedade. Assim, o futebol se constitui como mais um dos meios pelos quais a diferenciação entre mulheres $e$ homens se perpetua, estabelecendo os papéis que devem ser ocupados por cada um.

Nesse sentido, o objetivo do presente trabalho é identificar como se posicionam atletas de futebol feminino com longa vivência dentro da modalidade e que então, em alguns aspectos, não seguiram à risca determinadas normas de gênero². Para tanto, as seguintes problematizações foram elaboradas: como se situam as mulheres que tiveram suas carreiras provavelmente marcadas pelas questões suscitadas por esse desvio? De que maneira atletas de futebol feminino constroem e/ou representam por meio de memórias suas identidades corporais? Há em suas reminiscências marcas de pressões impostas para uma adequação aos modelos socialmente estabelecidos pelas normas de gênero?

\section{METODOLOGIA}

Na tentativa de responder tais questionamentos recorreu-se à História Oral. Metodologia que vem aumentando progressivamente seu campo de atuação nas últimas décadas (LOZANO, 2006) e que atende aos mais variados objetivos, principalmente em áreas como Filosofia, Sociologia, Psicologia e Antropologia (ALBERTI, 2008). No presente artigo ${ }^{3}$ ela serviu como base de elaboração e análise de entrevistas feitas com duas ex-atletas da seleção brasileira de futebol feminino, Dayane de Fátima da Rocha e Marina Toscano Aggio de Pontes, ambas com longa trajetória profissional em clubes brasileiros e europeus. As entrevistas duraram cinquenta e sete minutos e uma hora e vinte minutos, respectivamente, e foram posteriormente transcritas seguindo os pressupostos metodológicos propostos por Verena Alberti (2008). Vale salientar que os verdadeiros nomes das atletas foram utilizados porque o reconhecimento de suas carreiras e imagens públicas atuam como parte constitutiva da análise.

\footnotetext{
1 Cabe também salientar as conceituações levantadas por Weeks (1999) sobre os conceitos de sexo e gênero: a) sexo - conceito para indicar as diferenças anatômicas básicas, internas e externas ao corpo, que se vê como diferenciando homens e mulheres; b) gênero - termo usado para descrever a diferenciação social entre homens e mulheres.

2 Normas de gênero são aqui entendidas como as linhas tênues que dividem os comportamentos ditos adequados e culturalmente estabelecidos aos sexos masculino e feminino. Existem momentos e condições em que algumas fronteiras podem ser rompidas, sendo que aqueles ou aquelas que atuam nesse rompimento são geralmente considerados transgressores das normas impostas (SCOTT, 1995; ALTMANN, 1999). 3 Este estudo possui vínculo com a pesquisa denominada "Que tempo bom! Naquela época...: perscrutando as memórias e as narrativas do esporte", a qual possui aprovação do Comitê de Ética do Instituto de Ciências Humanas da Universidade de Brasília, sob o número CAAE 51225615.5 .0000 .5540
} 
O contato com as atletas foi feito a partir de conhecimento prévio da primeira autora deste artigo, já que esta convive no meio do futebol amador de Curitiba, no qual essas atletas estavam inseridas no momento da pesquisa. Dessa forma, vínculos sociais em comum permitiram que o convite para participação na pesquisa fosse feito por meio de telefone, quando os objetivos foram expostos. Posteriormente, então na data acordada para as entrevistas, as atletas assinaram um termo de consentimento livre e esclarecido autorizando a utilização de seus nomes e do conteúdo de suas entrevistas.

Sobre os mecanismos necessários a um trabalho com tal metodologia, Verena Alberti indica que:

Cabe ao pesquisador que trabalha com entrevistas de história oral atentar para a preciosidade de unidades narrativas [...], porque elas são capazes de comunicar experiências que vão além da trajetória particular de determinado entrevistado, dando conta de formas de elaborar o mundo próprias a uma geração, a um segmento profissional, a um campo do conhecimento, enfim (ALBERTI, 2004, p. 110-111).

Apesar disso, algo muito importante a se considerar é que "[...] até mesmo as pessoas mais moldadas pelos padrões culturais são, por essa mesma razão, unicamente individuais" (PORTELLI, 2010, p. 183). Assim, é necessário muito cuidado para que o conteúdo produzido no encontro entre entrevistado e pesquisador não seja tomado como norma absoluta.

Cabe ressaltar que, ao se trabalhar com História Oral, o pesquisador está também destinado à análise das interferências do trabalho da memória nas narrativas feitas por seus entrevistados, já que: "[...] Sem dúvida, a memória em si é gerada e estruturada de maneira específica, em função da oportunidade de contar uma história de vida e das circunstâncias em que isso acontece" (PATAl, 2010, p. 30). Ou ainda que:

[...] a memória é, acima de tudo, uma reconstrução continuamente atualizada do passado, mais do que uma reconstituição fiel do mesmo. [...] A ideia segundo a qual as experiências passadas seriam memorizadas, conservadas e recuperadas em toda sua integridade parece 'insustentável' (CANDAU, 2011, p. 9).

As ponderações supracitadas, prestadas por importantes nomes no estudo da memória social, ajudam a entender que todo trabalho narrativo é influenciado por variados fatores, intrínsecos e extrínsecos. Isso porque, ao relembrar, o entrevistado está postado diante de alguém que o escuta, e sua relação com essa pessoa tem considerável interferência na maneira como os fatos são contados, já que sua identidade também está sendo construída (CANDAU, 2011).

Mais uma vez em referência à função do entrevistador, que, no caso da História Oral, também é visto como produtor de fontes por provocar no entrevistado a rememoração de alguns tópicos úteis ao trabalho em questão, uma última, mas não menos relevante constatação, é que um trabalho desse tipo "[...] requer uma preparação criteriosa, que nos transforme em interlocutores à altura de nossos entrevistados, capazes de entender suas expressões de vida e de acompanhar seus relatos" (ALBERTI, 2004, p. 19).

\section{ENQUADRAMENTOS, PRESSÕES E FORMAÇÃO DE IDENTIDADE}

Dayane Rocha é uma atleta de futebol com passagens pelas seleções brasileiras universitária e principal. A atacante participou da campanha da medalha de prata com a seleção 
brasileira principal nas Olimpíadas de Atenas, em 2004, e conquistou a artilharia de dois campeonatos mundiais com a seleção brasileira universitária, em 2007 e 2009. Na época de realização da entrevista, ela estava atuando como atleta de futsal pela cidade de Colombo/PR e como professora de Educação Física na rede municipal e estadual de ensino.

Ao ser questionada sobre o papel exercido pelo futebol em sua infância, por meio de suas reminiscências, Dayane mostrou que a conhecida estranheza à prática de mulheres no futebol também esteve presente em seus primeiros passos na modalidade:

Com sete anos de idade meu pai decidiu me colocar em uma escolinha de futebol. Eu era a única menina no meio dos meninos. Sofri um pouco com isso no começo, porque, pense, eu sou de [19]85, então era bem o tempo em que o futebol feminino era muito descriminado e, sendo a única menina no meio dos meninos e podendo jogar uma categoria abaixo, eu era sempre acima deles e em função disso eu sofri muita discriminação, porque os pais vinham de fora e falavam assim: 'Ah como que uma menina joga no meio dos meninos e ainda é a camisa 10 do time?'. Isso foi um dos pontos negativos que eu tive no começo da minha carreira, mas meus pais, a partir disso, decidiram me apoiar, então eu fiquei dos sete aos quatorze anos na escolinha (ROCHA, 2016). ${ }^{4}$

Nesse caso, apesar de ser o relato de uma experiência individual, o episódio coadunase com os resultados da imposição dos papéis estabelecidos culturalmente às mulheres na sociedade brasileira, o que dificultou muito sua inserção na prática esportiva, principalmente daquelas modalidades que não primam pela graciosidade, leveza e plasticidade de movimentos. Sendo o futebol considerado seu mais significativo exemplo, ainda hoje, apesar de importante relativização, ele ainda não é aceito como uma prática para as mulheres (GOELLNER, 2005a; GOELLNER, 2005b).

Essa visão se amplia ao se analisar um trecho de entrevista de Marina Toscano Aggio, que também é ex-atleta da seleção brasileira principal. Ela atuou durante sua carreira por clubes europeus e brasileiros, tendo conquistado títulos importantes, como o Campeonato Brasileiro e a Copa do Brasil. Ao responder se havia resistência por parte dos meninos na primeira escola de futebol que participou, a zagueira afirmou que:

No início sim, eu lembro que quando eu fui fazer a inscrição quando a escolinha abriu, nós estávamos em 150 meninos, dentre os quais era só eu de menina, e todo mundo ficava me perguntando: 'O que você tá fazendo aqui?' 'O que você tá fazendo aqui?'. E eu falava: 'Eu vou jogar, eu vou treinar, eu vou ganhar o que vocês vão ganhar né, o mesmo conhecimento que vocês...', mas foi somente naquele momento, depois os meninos se acostumavam tanto com a minha presença, que quando eu não ia ou quando eu faltava nas aulas, eles ficavam me perguntando o porquê de eu ter faltado (AGGIO, 2016). ${ }^{5}$

Torna-se perceptível que a construção memorialística de ambas as entrevistadas dá indícios de que elas pouco se importaram com as ações de resistência realizadas sobre suas práticas esportivas e passaram por isso até com certa facilidade para continuar no futebol. $\mathrm{Ou}$, pelo menos, é isso o que desejam transparecer na construção de suas identidades perante o pesquisador (CANDAU, 2011). Vale salientar também que, segundo Marina, houve um rápido processo de aceitação e integração ao grupo de meninos, revelando que o estigma contra meninas praticantes de futebol não deve ser levado como uma regra, principalmente

4 Entrevista realizada com a atleta Dayane Rocha no ano de 2016, em Curitiba.

5 Entrevista realizada com a atleta Marina Toscano Aggio no ano de 2016, em Curitiba. 
quando se trata do convívio entre crianças. Tal experiência relatada pela atleta coaduna-se com as inferências feitas por Helena Altmann (1999) após analisar o convívio entre meninos e meninas no ambiente escolar, oportunidade na qual ela constatou que a liderança masculina não acontece de forma simples. Segundo a autora, existem momentos e episódios em que as meninas combatem esse domínio e diminuem sua relevância, sendo o futebol uma das atividades que possibilitam resistências e modificações nas relações entre homens e mulheres. Em todo caso, papéis que parecem ser de extrema importância na trajetória das futebolistas são aqueles realizados por suas famílias. Como pode ser observado nos excertos abaixo:

Nessa época eu tinha sete anos [início da prática em meio a meninos], estamos falando de 1992 por aí, era uma época em que o futebol feminino tinha muito preconceito, mas muito mesmo. Lembro assim até hoje que muitas vezes meu pai saiu na porrada com outros pais porque eles falavam: 'É, menina tem que estar ajudando a mãe lavar louça, única coisa que sabe fazer é crochê'. Foi uma época em que eu sofri preconceito e isso afetou a minha família muitas vezes. Por muitas vezes minha mãe falou que eu não iria jogar mais futebol e meu pai defendia que eu iria jogar sim, dizendo que enquanto ele pudesse lutar junto comigo eu iria jogar. Minha mãe sempre foi o lado mais fraco, porque, emocionalmente, aquilo chocava ela, e meu pai era o elo mais forte comigo. Pra se ter noção, quando eu fiz dezessete anos meu pai era meu treinador, pois já havia criado um elo muito grande com o futebol feminino, se identificou e brigou pela causa, muitas vezes até tirando [dinheiro] do bolso (ROCHA, 2016).

Esse habitus ${ }^{6}$ familiar que foi adquirido dentro de casa por meio dos meus pais, que meus pais nunca impediram que eu jogasse, eu levei por toda a vida, e aí eu vou levar como professora, como profissional, que eu também não admito isso, bem como vou levar como mãe, possivelmente, para o meu filho, porque uma vez que a gente adquire um hábito dentro da família, reestruturá-lo dentro das outras instituições não é fácil, mas como eu tinha esse habitus e esse habitus foi muito positivo, provavelmente eu vou levar para o resto da minha vida como positivo (AGGIO, 2016).

Ambos os trechos demonstram que o apoio familiar, principalmente dos pais, foi essencial para a manutenção das atletas na prática esportiva, já que a segurança vinda desse ambiente parece trazer uma ótima proteção e acolhimento diante dos problemas decorrentes de preconceito que pudessem ocorrer (KNIJNIK; VASCONCELLOS, 2003; MOURA et al. 2017). Além disso, duas situações paradoxais são percebidas no trecho de fala da atleta Dayane Rocha: seu pai parecia ter uma visão mais aberta que sua mãe sobre a possibilidade de que ela rompesse com as normas de gênero impostas historicamente pelo futebol, dando indícios de que, muitas vezes, a própria mulher é atuante na permanência das desigualdades; ao mesmo tempo, o pai de Dayane usa de violência física, um dos recursos tidos como típicos dos enquadramentos da masculinidade (CONNELL; MESSERSCHMIDT, 2013), para defender condições de igualdade de tratamento entre homens e mulheres.

Perceptível é que as duas mulheres demonstraram ser muito convictas sobre suas escolhas e muito seguras em relação aos seus posicionamentos durante todo o processo de entrevista. Atribui-se a isso o considerável sucesso que ambas atingiram em suas trajetórias profissionais, já que chegaram à seleção brasileira e conquistaram relativa autonomia financeira jogando em clubes europeus - os quais, declaram, são agremiações integrantes de um cenário

6 Habitus aqui é escrito com essa grafia por se entender que a entrevistada está se utilizando do conceito de Pierre Bourdieu, já que anteriormente fui informada por ela de que ela havia recém terminado seu mestrado na área de Educação, usando exatamente como base teórica as obras do sociólogo francês. 
completamente diverso da prática futebolística no Brasil. Dessa forma, elas parecem estar situadas em um patamar que as permite criticar e opinar categoricamente sobre vários aspectos relacionados à modalidade em que foram atletas de ponta.

Essa segurança é também facilmente perceptível ao se transitar por assuntos relacionados ao gênero e aos padrões de beleza dentro do futebol. Marina usou as seguintes palavras para expressar a sua indignação com os constantes questionamentos sobre a viabilidade de jogar futebol e ao mesmo tempo apresentar-se como mulher:

Então assim, uma das minhas críticas com relação à própria mídia é que a mídia influencia muito a relação mulher e esporte. Então, ela quer juntar todos esses fatores, mas, na realidade, isso é muito diferente, porque a 'mulher esporte' é aquela mulher que treina todo dia debaixo de sol, não é bonita, não é maravilhosa e não usa salto, apesar do lindo corpo que ela tem. A 'mulher mulher', que a sociedade quer que ela seja, é uma mulher que é aquela do cotidiano, que não pratica esportes, desculpa, mas essa é a verdade (AGGIO, 2016).

Essa afirmação indica que os posicionamentos de Marina são influenciados por uma aproximação com os conceitos de gênero em sua formação acadêmica. Por outro lado, do mesmo modo que criticou essa pressão exercida sobre a mulher atleta, Marina deixou transparecer que acredita ser necessário um cuidado com a aparência para melhorar a imagem do futebol feminino e considera uma "evolução" o fato de ter reduzido muito o número, na atualidade, de atletas com características físicas próximas ao mundo masculino (FERRETI et al., 2011):

Então eu acredito que toda essa visão que nós fomos lá fora e buscamos, eu não falo só eu não, porque eu tive um trabalho com mais de cem meninas aqui no Novo Mundo e eu prezava muito pela estética, porque infelizmente, o nosso país trabalha com essa função estética, essa cultura estética corporal. Infelizmente, nós temos a visão de que a mulher não pratica o futebol feminino, que a mulher ela é masculina, claro, com muitas exceções, hoje o futebol está muito mais evoluído do que antigamente, a mulher tem o cabelo comprido. E umas das minhas brigas em relação a isso é que toda vez que nós íamos dar entrevista, eu tinha que estar linda, eu tinha que estar arrumada, eu tinha que estar perfeita nos programas de televisão, porque as pessoas queriam ver uma Marina que eu não era em campo (AGGIO, 2016).

Tal excerto de fala traduz um pouco do paradoxo em que se encontram essas atletas. Ao mesmo tempo em que defendeu uma padronização, Marina usou a palavra "infelizmente" para opinar sobre a valorização dos padrões de beleza estabelecidos para as mulheres e criticou a expectativa empregada sobre ela para que estivesse bela ao deixar o campo de jogo.

Dayane apresenta posicionamento parecido, já que, ao ser questionada se sofreu preconceito durante sua carreira, respondeu parecendo entender que as atletas deveriam adequar suas imagens para que não sofressem preconceito:

Olha, eu não sofri porque eu sempre mantive a aparência que eu quis. Eu sempre tive cabelo comprido, eu sempre me vesti bem. Mas assim, eu tenho amigas que sofreram muito preconceito pelo fato de ter o cabelo curto, pelo fato de não se vestir bem, pelo fato de deixar decair a imagem (ROCHA, 2016).

Essas obrigações referentes ao corpo que se mostra à sociedade são bem problematizadas por David Le Breton:

É conveniente que uma etiqueta corporal varie segundo o sexo do interlocutor, seu status, sua idade, o grau de parentesco, ou de familiaridade, o contexto da 
interação, etc. Toda conduta que escape à sua definição social é ameaçada pela inconveniência. Ela pode suscitar a vergonha daquele que toma consciência de ter rompido um quadro estabelecido, e o mal-estar daquele que é confrontado a esse afastamento (LE BRETON, 2011, p. 200).

No caso de uma parcela de mulheres praticantes de futebol, adepta ao corte de cabelo curto, ao uso de roupas largas e comportamento mais despojado e menos recatado, elas estão transgredindo importantes normas de gênero, por meio das quais se espera que elas sejam delicadas, graciosas e marcadamente diferentes dos homens. Diferenciação esta que deveria ocorrer pelo vestuário, pelo cabelo comprido e vistoso e, acima de tudo, por um comportamento condizente com seu sexo, pensando-se em padrões estabelecidos principalmente pelo universo masculino. Apesar do posicionamento de aceitação em determinados momentos, em outros a atleta se mostrou contrariada com a situação, mostrando claros sinais de resistência aos valores impostos a mulheres esportistas:

A gente teve um problema uma vez dentro da seleção, que uma marca de shampoo queria patrocinar a gente. Foram fazer uma contagem e nós éramos em oito de cabelo comprido e praticamente doze eram de cabelo curto. E a marca do shampoo falou: 'Vou patrocinar quem? Vou patrocinar as oito só que tem cabelo comprido?'. 'Ah tá, porque as que têm cabelo curto não lavam o cabelo?' Aí a gente entendeu que era mais preconceito, porque menina tinha cabelo curto, entendeu? (ROCHA, 2016).

É nítido que as atletas não concordam com as atitudes supostamente preconceituosas em relação àquelas meninas que jogam futebol e possuem características consideradas desviantes ao padrão estabelecido ao mesmo tempo em que tentam deixar claro que elas nunca sofreram nenhum tipo de preconceito, justamente por afastarem-se de tais características. Ao examinar tal necessidade de afirmação, considera-se que "[...] através desse trabalho de reconstrução de si mesmo o indivíduo tende a definir seu lugar social e sua relação com os outros" (POLLAK, 1989).

Essas organizações de memória para a formação de identidades parecem ser uma necessidade latente às atletas. Se tempos atrás estas viam a urgência de aproximação ao universo masculino para serem aceitas em lócus tão marcadamente dominado por homens, como é o futebol, hoje se veem na obrigação de desvincular suas imagens de tais enquadramentos (KNIJINIK; SOUZA, 2004), como pode mais uma vez ser notado em um trecho de fala de Marina Toscano. Ao ser questionada sobre a existência de algum tipo de imposição por parte da Confederação Brasileira de Futebol (CBF) em relação às normatizações de gênero, a atleta indicou: "Eu não cheguei a presenciar nenhum tipo de imposição sobre isso, mesmo porque a minha imagem sempre foi muito feminina e eu sempre me preocupei muito com isso" (AGGIO, 2016).

Em alguns relatos, pode-se observar que as pressões referentes a essas normatizações já aconteceram de forma explícita e extremada. Dayane relatou o fato de que a própria CBF trabalhou para adequar os corpos e a imagem das atletas aos padrões desejados pela mídia, aconselhando que as meninas deixassem seus cabelos mais compridos e trazendo para a concentração da seleção brasileira profissionais de beleza, como manicures, pedicures e cabeleireiros. Já Marina narrou um episódio protagonizado pela Federação Paulista de Futebol em 2007. A entidade contratou modelos profissionais para atuarem no campeonato paulista daquele ano, na tentativa de elevar o padrão estético da competição. Outras vezes, a pressão acontece de forma mais camuflada, como novamente contou Marina: 
Então assim, uma vez, uma repórter: 'Ah, mas você passa batom? Você passa isso?' Eu disse pra ela assim (depois de muitos anos a gente fala o que a gente pensa): 'Você veio falar da Marina atleta ou da Marina mulher? Porque se for da Marina mulher nós vamos responder essa pergunta, mas a Marina atleta ela não entra em campo cheirosa, ela não entra em campo com rímel, porque o rímel borra, porque eu tenho noventa minutos em baixo de um sol pra correr e a Marina atleta ela sua e ela necessita de músculos pra correr e ela não é tão feminina como você gostaria que ela fosse. Agora se você quiser falar da Marina mulher eu vou dizer pra você, que a minha vida fora de campo é assim, com maquiagem, com salto, com tudo aquilo que a sociedade quer ver' (AGGIO, 2016).

Nesse excerto, a irritação da atleta é notória. Apesar de se colocar como adequadamente inserida dentro do padrão estabelecido de beleza, Marina viu essa segurança abalada pelo fato de determinados indivíduos - uma mulher, inclusive - virem de "fora" e duvidar disso, ao relacionar sua prática com uma possível "falha" na elaboração da imagem a qual toda mulher deveria seguir. Essa "falha" se estabelece porque o corpo deve:

[...] se dissolver nos códigos em vigor, e cada um deve poder encontrar em seus interlocutores, como em um espelho, suas próprias atitudes corporais e uma imagem que não a surpreenda. É nesse sentido que aquele que não joga o jogo, deliberadamente ou à sua revelia, provoca um incômodo profundo. [...] A diferença transforma-se em estigma mais ou menos altamente afirmada (LE BRETON, 2011, p. 212-213).

Essa diferença em relação aos sexos nada mais é do que uma construção social que pode variar seu nível de distanciamento e influência sobre os corpos. Novamente na colaboração de Le Breton tem-se que:

Em nossas sociedades, o menino recebe uma educação com relação à dor ligada à imagem de virilidade, de força do caráter. Em princípio, os pais esforçam-se para impedir as tendências para a emotividade ou para a negligência. 0 mais depressa possível, ele deve assimilar as qualidades que imaginamos serem as do homem; ao contrário, toleramos facilmente e até mesmo encorajamos, as manifestações de sensibilidade da menina: as lágrimas e o lamento são menos admitidos no menino do que na menina, supostamente mais delicada. A educação transforma assim as crianças em atores conforme a imagem da mulher e do homem em vigor na sociedade (LE BRETON, 2006, p. 54).

Duas importantes questões vêm à tona com a supracitada constatação. Primeiro, as imposições sociais acontecem tanto para homens quanto para mulheres, ou seja, sobre o menino também recaem obrigações sobre seus corpos e comportamentos que certamente provocam os mesmos efeitos de subversão que recaem sobre as meninas, mas esse é um tema que não cabe ao presente trabalho. Segundo, o sociólogo usa muito bem os verbos de ação na primeira pessoa do plural - todos são participantes e agentes nesses processos de enquadramento social do sexo presente nos corpos.

\section{CONSIDERAÇÕES FINAIS}

O processo de entrevistas revelou que existem nas reminiscências das atletas algumas marcas de pressões exercidas para uma adequação às normas de gênero, que ocorreram - ora de forma explícita e agressiva ora de maneira mais camuflada - sobre os corpos de jogadoras de futebol. As reflexões de David Le Breton colaboraram com a análise ao mostrar que 
o incômodo com o diferente é sentido pelos agentes sociais pelo fato de que há o desejo de que os corpos de dissolvam nas similaridades, ou seja, as coisas em seus "devidos lugares" trazem o sentimento de organização e segurança social e tudo o que foge desse esquema é tratado como desviante e passível de retaliação. No caso do futebol de mulheres, isso se torna bem perceptível, já que as normas de gênero desrespeitadas por algumas dessas atletas atingem variadas bases dessa organização social já definida, principalmente em relação à aparência, vestuário e comportamento (KNIJNIK; SOUZA, 2004; GOELLNER, 2005b; MOURA et al., 2017).

Por essa razão, as atletas entrevistadas, no processo de formação de identidade elaborado pela memória, tentam ao máximo se afastar de uma imagem que pudesse as colocar próximas a esse estigma. Com afirmações de que sabem sobre o preconceito e com 0 conhecimento de que ele é bem comum, as atletas se dizem imunes e se definem como mulheres adequadas às normas de gênero, a ponto de justificar que, por esse motivo, o preconceito perante elas não seria possível. Apesar disso, alguns aspectos de suas memórias revelam que elas tiveram dificuldades na inserção no futebol e/ou, até mesmo, sofreram desconfiança pelo fato de praticarem modalidade tão marcada por características tidas socialmente como masculinas.

Por fim, foi notável que essas atletas, ao mesmo tempo em que se sentem prejudicadas por algumas pressões exercidas, agem elas mesmas na consolidação dos padrões que, aparentemente, deveriam ser seguidos, já que defendem uma mudança na aparência das jogadoras de futebol para que possa haver um desenvolvimento e uma aceitação maior das mulheres na modalidade. Posicionamento entendido como paradoxal. Entretanto, não é demasiado reforçar que a pesquisa não apresenta um panorama geral sobre as intenções e vivências da atleta mulher no futebol, haja vista que os roteiros não aprofundaram questões como as diferenças sociais e raciais.

\section{REFERÊNCIAS}

ADELMAN, Miriam. Mulheres no esporte: corporalidades e subjetividades. Movimento, v.12, $\mathrm{n}$. 1, p. 11-29, jan./abr. 2006.

ALBERTI, Verena. Histórias dentro da história. In: PINSKY, Carla Bassanezi (Org.). Fontes históricas. São Paulo: Contexto, 2008. p. 155-202.

ALBERTI, Verena. Ouvir Contar: textos em história oral. Rio de Janeiro: Editora FGV, 2004.

ALTMANN, Helena. Marias (e) homens nas quadras: ocupação do espaço físico escolar.

Educação \& Realidade, v. 24, n. 2, p. 157-173, jul./dez. 1999.

CANDAU, Joel. Memória e identidade. São Paulo: Contexto, 2011.

CONNELL, Robert; MESSERSCHMIDT, James. Masculinidade hegemônica: repensando o conceito. Estudos Feministas, v. 21, n. 1, p. 241-282, jan./abr. 2013.

FERRETI, Marco Antônio de Carvalho et al. O futebol feminino nos jogos olímpicos de Pequim.

Motriz, v.17, n. 1, p.117-127, jan./mar. 2011. 
GOELLNER, Silvana. Bela, maternal e feminina: imagens da mulher na Revista Educação Physica. 1999. 187f. Tese (Doutorado) - Faculdade de Educação, Universidade Estadual de Campinas, Campinas, 1999.

GOELLNER, Silvana. Mulher e esporte no Brasil: entre incentivos e interdições elas fazem história. Pensar a Prática, v. 8, n. 1, p. 85-100, jan./jun. 2005a.

GOELLNER, Silvana. Mulheres e futebol no Brasil: entre sombras e visibilidades. Revista Brasileira de Educação Física e Esportes, v. 19, n. 2, p. 143-151, abr./jun. 2005b.

KNIJNIK, Jorge Dorfman; SOUZA, Juliana Sturmer Soares. Diferentes e desiguais: relações de gênero na mídia esportiva brasileira; In: SIMÕES, Antonio Carlos; KNIJNIK, Jorge Dorfman (Org.). 0 mundo psicossocial da mulher no esporte: comportamento, gênero, desempenho. São Paulo: Aleph, 2004. p. 191-212.

KNIJNIK, Jorge Dorfman; VASCONCELLOS, Esdras Guerreiro. Sem impedimento: o coração aberto das mulheres que calçam chuteiras no Brasil. In: COZAC, João Ricardo. Com a cabeça na ponta da chuteira: ensaios sobre a psicologia do esporte. São Paulo: Annablume/Ceppe, 2003. p. 73-90.

LE BRETON, David. A sociologia do corpo. 2. ed. Petrópolis: Vozes, 2006.

LE BRETON, David. Antropologia do corpo e modernidade. Petrópolis: Vozes, 2011.

LOURO, Guacira Lopes. Gênero, sexualidade e educação: uma perspectiva pós-estruturalista. 6. ed. Petrópolis: Vozes, 1997.

LOZANO, Jorge Eduardo Aceves. Prática e estilos de pesquisa na história oral contemporânea. In: FERREIRA, Marieta de Moraes; AMADO, Janaína. (Org.). Usos e abusos da História Oral. Rio de Janeiro: Editora FGV, 2006. p. 15-25.

MARTINS, Leonardo Tavares; MORAES, Laura. O futebol feminino e sua inserção na mídia: a diferença que faz uma medalha de prata. Pensar a Prática, v. 10, n. 1, p. 69-81, jan./jun. 2007.

MORAES E SILVA, Marcelo; FONTOURA, Mariana Purcote. Educação do corpo feminino: um estudo na Revista Brasileira de Educação Física (1944-1950). Revista brasileira de Educação Física e Esportes, v. 25, n. 2, p. 263-75, abr./jun. 2011.

MOURA, Giovanna Xavier et al. Mulher e esporte: o preconceito com as atletas de Rugby da cidade de Maringá-PR. Motrivivência, v. 29, n. 50, p. 17-30, 2017.

PATAI, Daphne. História oral, feminismo e política. São Paulo: Letra e Voz, 2010.

POLLAK, Michael. Memória, esquecimento, silêncio. Estudos Históricos, v. 2, n. 3, p. 3-15, 1989.

PORTELLI, Alessandro. Ensaios de história oral. São Paulo: Letra e Voz, 2010.

SALVINI, Leila; MARCHI JUNIOR, Wanderley. Uma história do futebol feminino nas páginas da Revista Placar entre os anos de 1980-1990. Movimento, v. 19, n. 1, p. 95-115, jan./mar. 2013.

SCOTT, Johan Wallach. Gênero: uma categoria útil de análise histórica. Educação \& Realidade, v. 20, n. 2, p. 71-99, jul./dez. 1995.

WEEKS, Jeffrey. O corpo e a sexualidade. In: LOURO, Guacira Lopes (Org.). 0 corpo educado - pedagogias da sexualidade. Belo Horizonte: Autêntica, 1999. p. 35-82. 


\section{Apoio:}

Coordenação de Aperfeiçoamento de Pessoal de Nível Superior (Capes). 